\title{
FEWER REFERRALS TO SWEDISH EMERGENCY DEPARTMENTS AMONG NURSING HOME PATIENTS WITH DEMENTIA, COMPREHENSIVE COGNITIVE DECLINE AND MULTICOMORBIDITY
}

\author{
A.-G. MAMHIDIR ${ }^{1,2}$, A. WIMO ${ }^{3}$, A. KIHLGREN ${ }^{4}$ \\ 1. Faculty of Health and Occupational Studies, Department of Health and Caring Sciences, University of Gävle, SE-801 76 Gävle, Sweden; 2. Department of Public Health and Caring \\ Sciences, Uppsala University, Sweden; 3. KI Alzheimer's Disease Research Center, Department of Neurobiology, Care Sciences and Society, Karolinska Institute, SE-171 77 Stockholm, \\ Sweden; 4. Health Academy Örebro University, SE-701 82 Örebro, Sweden. Corresponding author: A-G Mamhidir, Faculty of Health and Occupational Studies, Department of Health \\ and Caring Sciences, University of Gävle, SE-801 76 Gävle, Sweden. Tel.: +46 2664 82 48, Fax: +46 266482 35, E-mail address: anamar@hig.se
}

\begin{abstract}
Objectives: The objective was to describe the extent to which nursing home patients had cognitive impairments and were diagnosed with dementia. Furthermore, to describe and compare multicomorbidity, health status and drug use in the three subgroups; dementia diagnosis/not referred, dementia diagnosis/referred and no dementia diagnosis/not referred to an emergency department (ED) over a one-year period. Methods: A crosssectional follow-up study was carried out in Sweden. RAI/MDS assessments were conducted on 719 patients in 24 nursing homes, of whom 209 were referred to EDs during a one-year period, accounting for 314 visits. This study involved an extensive examination of the population. Results: The 719 patients were reported to suffer from comprehensive cognitive impairments, which not accorded with the dementia diagnoses, they were significantly fewer. Cognitive decline or dementia diagnosis contributed to a significant decrease of referrals to EDs. Patients with dementia diagnosis/not referred had difficulties understanding others, as well as impaired vision and hearing. Patients with dementia diagnosis/referred usually understood messages. Low BMI, daily pain, multicomorbidity and high drug consumption occurred in all groups. Patients with no dementia diagnosis/not referred had significantly less multicomorbidity. Neuroleptica was significantly more prevalent among those with dementia diagnosis. Conclusion: Dementia remains undetected. Patients with cognitive decline and dementia are probably as sick as or even worse than others but may, due to low priority be undertreated or referrals avoided with the objective to provide good care in the setting. Observational studies are needed to identify what is done and could be done in referral situations.
\end{abstract}

Key words: Nursing home, dementia, cognitive impairment, referrals, emergency department.

\section{Introduction}

Elderly people are often referred to emergency departments (ED). The care provided in such departments differs from other care as the patients are in need of urgent attention, the duration of visits is usually short and decisions have to be made quickly. Kihlgren et al. (1) described a wide range of illnesses and mental states among nursing homes $(\mathrm{NH})$ patients referred to an ED. More than $20 \%$ of patients admitted to an ED reported poor quality of the ED environment such as little attention to the patients' whole life situation on the part of nurses (2). According to Kihlgren et al. (3), older patients at EDs were exposed to a lack of good routines during the waiting period, e.g. unpleasant and unnecessary waiting, which gave rise to negative feelings among them. A literature review by Grief et al. (4) demonstrated gaps in knowledge among ED staff related to the nursing care of older patients. The ED milieu was described as inappropriate for meeting older patients' needs (5).

Many older patients admitted to EDs have conditions such as infections, trauma, dehydration and polypharmacy that can cause cognitive impairment, while some have dementia. In the latter case, hospital admission can be hazardous (6). Condelius et al. (7) indicated that multimorbidity contributed to referrals to hospital, as one of the main predictors of admission was the number of medical diagnosis groups.

Received November 25, 2011

Accepted for publication January 19, 2012
Lower utilization of hospital care has been described among $\mathrm{NH}$ patients compared to older patients cared for at home $(7,8)$. However, according to a Scottish study that reviewed general practitioner case notes, between $8 \%$ and $40 \%$ of $\mathrm{NH}$ patients referred to an ED could have been managed in the nursing home. Furthermore, $71 \%$ of the patients were returned to the $\mathrm{NH}$ by non-ambulance transport (9). Older patients are a vulnerable group often diagnosed as having multicomorbidity and various functional impairments resulting in complex needs $(7,10)$. This group is frequently transferred back and forth between the different health and social care system levels (11). There have also been great changes in the health and elder care infrastructure. The number of hospital beds was reduced by $55 \%$ between 1992 and 2003, from 58,000 to 26,000, and a further reduction to 24,000 took place in 2010 (12). The duration of each hospitalization decreased by 7.6 days, a change of almost $50 \%$ (13). The number of persons living in NHs in Sweden decreased from 118,700 in 1998 to 110,900 in 2003 (14) and to 95,000 in 2010 (15).

One frequently mentioned reason for referral to EDs is inappropriate drug use. Bergman et al. (16) assessed the quality of drug therapy by the number of prescribed drugs per $\mathrm{NH}$ patient and revealed that more than $70 \%$ had one or more potentially inappropriate prescriptions. In a study that included 3,705 participants from NHs and special care units for dementia 
(17), the mean number of prescribed drugs was 10.3 per patient. The proportion of individuals prescribed psychotropic drugs was $80 \%$ in $\mathrm{NHs}$ and $85 \%$ in special care units for dementia. According to Olsson et al. (17), anticholinergic drugs were prescribed for approximately $20 \%$ of all $\mathrm{NH}$ patients and a high rate of psychotropic drug use ( $>=80 \%$ ) was reported.

Dementia is becoming a greater problem in health care globally (18), due to an increase in the number of people affected. In Sweden, the number of people suffering from dementia increased from 133, 000 to 148,000 between 2000 and 2008 (14). Disorders such as dementia that cause cognitive impairment are common in long term institutional care. Mamhidir et al. (19) found that cognitive impairment was present in $67 \%$ of $\mathrm{NH}$ patients and Nordberg et al. (20) reported $62 \%$. Such patients often exhibit symptoms that are difficult to interpret. Although they have the same illnesses as younger patients, their symptoms differ as they often have several illnesses, which make the symptoms and diagnosis more complex. These patients often present with acute and serious medical and psychosocial problems (10).

Patients with dementia are at risk of not receiving adequate assessment or treatment due to their relative lack of communication skills (21). These patients are doubly vulnerable, as information gaps between the NHs and the EDs concerning the patients' health status commonly occur and the clinical impact of this is not clear (22). Essential information provided to emergency department patient care was significantly increased by using a transfer form (23). In contrast, McCloskey (24) described that although organizationspecific forms were used, they contributed little to the sharing of information between the NHs and EDs. Detection and diagnosis of cognitive dysfunction is critical for the quality of dementia care (25). Douzenis et al. (26) described undetected dementia as problematic among older hospital patients. Undetected cognitive impairment can lead to inappropriate care interventions and follow-ups in this group $(27,28)$.

Mamhidir et al. (19) found that of 719 patients living in NHs, $28 \%$ had moderate and $39 \%$ severe cognitive impairment, when assessed by the Cognitive Performance Scale (28). Dementia was diagnosed in $36 \%$. Within this group of $\mathrm{NH}$ patients, 209 (29\%) were referred to an ED 314 times in the course of a year (1). Questions were raised about patients with diagnosed dementia and cognitive decline, as although they received fewer referrals they are likely to have the same level of disabilities. More research is needed, since these individuals may be undetected and undertreated. This paper therefore focuses on further investigation of Kihlgren's results (1). The aim was to describe the extent to which nursing home patients had cognitive impairments and were diagnosed with dementia. An additional aim was to describe and compare multicomorbidity, health status and drug use in the following three subgroups; dementia diagnosis/not referred, dementia diagnosis/referred and no dementia diagnosis/not referred to an emergency department (ED) in the course of a year.

\section{Materials and methods}

\section{Sample and setting}

The present investigation is part of a cross sectional followup study, in which disabilities, resources and needs among older patients in NHs were assessed. The study was conducted in ten municipalities in a county in Sweden in the period 20002002 (18) and was approved by managers of each community and by the Regional Research Ethical Committee (99310-17). The county is situated in the middle of Sweden and represents $\mathrm{NHs}$ from both rural and urban areas. A random sample of 24 NHs with a total of 800 individuals was initially recruited. 719 elderly patients participated, which represented $16 \%$ of all $\mathrm{NH}$ residents. Inclusion criteria were aged $75+$ years and living permanently in a community-managed $\mathrm{NH}$. What the different units defined as NHs was not always clear. Most NHs had mixed living settings (76\%) i.e. groups of individuals with both cognitive and functional disabilities. Others lived in group livings for persons with dementia (4\%). Yet other persons resided low staffed service houses $(20 \%)$ and had individual apartments. In the NH settings food for example was delivered from central kitchens while others prepared the food on site. The persons in service houses had access to a restaurant for their meals or could have them delivered. One of the NHs was defined as a group facility for patients with dementia and $21 \%$ of the persons lived in service houses i.e. and while the rest of the patients lived in mixed settings.

At the follow-up after one year the mixed settings and services houses reported a mortality of $26 \%$, respectively and in the group living of dementia the mortality was $19 \%$. All NHs were guaranteed regularly visits by a general practitioner once a week due to a county council agreement. Geriatricians could be connected to a NH but it was unusual since there was a shortage of that kind of specialist. Figure 1 presents the patients initially recruited, including the 81 individuals who withdrew, moved or died before the data collection started. The present study focuses on the $29 \%(n=209)$ referred to an ED over a one-year period (1).

\section{Procedure}

The management of the NHs gave informed consent to participate in the study. Verbal and written information was provided to all patients, relatives and staff members. It was explained that participation was voluntary, confidentiality was guaranteed and that the participants could withdraw from the study at any time without giving a reason. The $\mathrm{NH}$ managers obtained individual verbal as well as written consent from the patients and/or their relatives.

Before the start of the assessments, interested enrolled nurses, registered nurses and physiotherapists $(\mathrm{N}=150)$ from the $24 \mathrm{NHs}$ were trained in how to use the assessment instrument by the research team. Thereafter, these care providers carried out baseline as well as follow-up assessments after one year. More detailed information about the sample size, recruitment 
procedures and other considerations before the follow up is provided by Mamhidir et al. (19).

\section{Figure 1}

Overview including the initially recruited patients at the start of the study, dropouts, the baseline study group and, the referrals to the Emergency Department over a one-year period

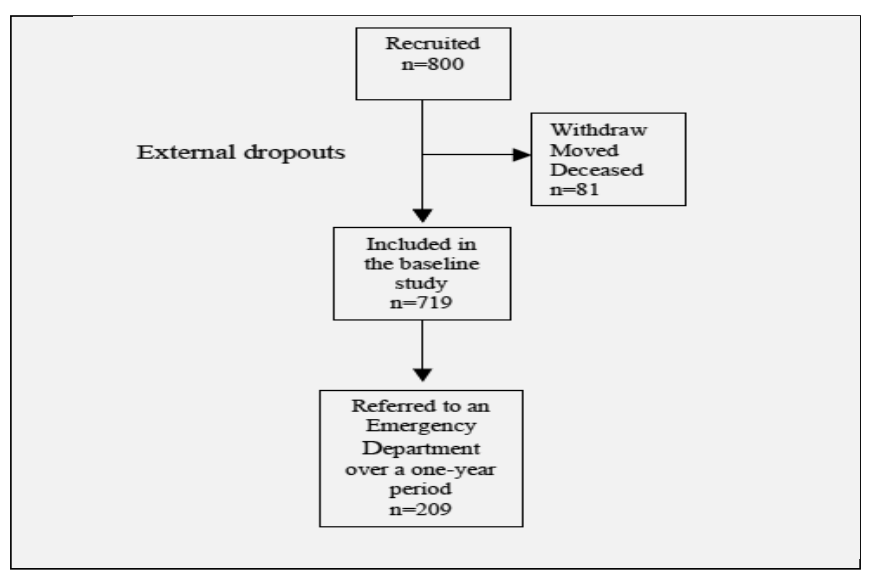

\section{Data collection}

The RAI/MDS focuses on patients' functional capacity, resources and needs, is internationally established, valid and reliable (29) and provides a comprehensive assessment of older patients receiving health care $(30,31)$. Selected items from this baseline database of patients' characteristics were extracted for the present study: age, gender, cognitive and functional capacity, medical diagnosis and drug consumption. All medical diagnoses were drafted from each person's medical record.

Items representing two RAI/MDS scales were used; the Cognitive Performance Scale (CPS-scale), which ranges from 0-6 (normal cognitive capacity to severe cognitive dysfunction) (32) and the Activities of Daily Living (ADL) scale, which ranges from 4-18 (totally independent to totally dependent) and has a cut-off limit of $>10$ denoting severe functional impairment (33).

Patient characteristics from the baseline data $(n=719)$ revealed; an aged population 85.8(5.6) years and with a majority of females $(71 \%)$. The individuals had stayed in the settings for 2-4 years but the high SDs indicates a large variability (Table 1). The stay time for persons in group livings for dementia was as expected shorter compared to the other type of settings.

Thirty-nine percent had severe cognitive impairment (CPS, 4-6), while serious ADL dysfunction (ADL-score 10-18) was observed in $38 \%$. Dementia was diagnosed in $36 \%$, depression and stroke in $17 \%$ and $15 \%$ respectively. Six medications per day were administered (range 4.0-9.0) and the most frequently used drug groups the previous week were diuretics and analgesics (Table 1).

\section{Table 1}

Patient characteristics, drugs taken and drug groups used during the previous seven days. Information retrieved from the RAI/MDS data at baseline $(n=719)$.

\begin{tabular}{|c|c|}
\hline & $\begin{array}{l}\text { atients at baseline } \\
\mathrm{n}=719(\%)\end{array}$ \\
\hline Age, mean (SD) & $85.8(5.6)$ \\
\hline Female & $513(71)$ \\
\hline Dementia & $258(36)$ \\
\hline Cognitive Performance Scale ${ }^{1}$, CPS 0-1 & $241(34)$ \\
\hline CPS 2-3 & $198(28)$ \\
\hline CPS 4-6 & $280(39)$ \\
\hline Advanced ADL dependency, ADL-score $10-18^{2}$ & $190(38)$ \\
\hline Parkinson's disease & $44(6)$ \\
\hline Depression & $110(15)$ \\
\hline Stroke & $121(17)$ \\
\hline Aphasia & $25(4)$ \\
\hline \multicolumn{2}{|l|}{ Mean staying time in care setting (SD) } \\
\hline Nursing home & $1202(1204)$ \\
\hline Mixed setting & $1192(1219)$ \\
\hline Service house & $1335(1213)$ \\
\hline Group living & $674(576)$ \\
\hline $\begin{array}{l}\text { Number of prescribed drugs during the } \\
\text { previous } 7 \text { days }^{3}\end{array}$ & $6(4.0-9.0)$ \\
\hline \multicolumn{2}{|l|}{ Drug groups used the previous week } \\
\hline Neuroleptics & $104(15)$ \\
\hline Sedatives & $160(22)$ \\
\hline Antidepressives & $243(34)$ \\
\hline Hypnotics & 208 (29) \\
\hline Diuretics & 355 (49) \\
\hline Analgetics & $294(41)$ \\
\hline
\end{tabular}

1 = CPS-scale 0-6; Cognitive Performance Scale; Normal and mildly impaired $=0-1$, Moderately impaired $=2-3$, Severely impaired $=4-6.2=$ ADL score $4-18$; Activities of Daily living; Normal/moderately impaired function (4-9) and severe dysfunction (10-18). $3=$ Median (range).

\section{Data analysis}

The RAI/MDS data as well as the community nurses' documentation were analysed using the SPSS 18.0 (SPSS Inc., Chicago, IL, USA). Descriptive statistics are presented as frequencies, percentages and mean SD. The Chi-square test was used and a p-value of less than 0.05 regarded statistically significant.

\section{Results}

\section{Dementia diagnosis vs. cognitive impairment}

First we used two approaches to describe cognitive impairment and dementia because it was of interest to explore how these approaches accorded with each other. In the group of 719 patients there were significantly fewer diagnoses of dementia $(\mathrm{p} \leq 0.001)$ compared to cognitive impairment $(49 \%)$ as assessed by the CPS-scale (CPS 2-6). On the other hand, some participants who had a diagnosis of dementia $(n=5)$ did not exhibit cognitive decline, which was interpreted as a typing error (Table 2). 
The Journal of Nutrition, Health \& Aging(C)

Volume 16, Number 10, 2012

\section{FEWER REFERRALS TO SWEDISH EMERGENCY DEPARTMENTS AMONG NURSING HOME PATIENTS WITH DEMENTIA}

Table 2

Diagnosed dementia among older patients in nursing homes versus cognitive decline according to the Cognitive

Performance Scale, CPS-scale $(n=719)$

\begin{tabular}{lccc}
\hline & $\begin{array}{c}\text { Normal cognitive } \\
\text { capacity }^{1} \\
(\boldsymbol{\%})\end{array}$ & $\begin{array}{c}\text { Impaired cognitive } \\
\text { capacity }^{1} \\
(\boldsymbol{\%})\end{array}$ & $\mathbf{p}^{4}$ \\
\hline Dementia diagnosis & & & \\
No dementia diagnosis $^{23}$ & $236(51)$ & $251(98)$ & \\
\hline
\end{tabular}

1 = CPS-scale 0-6; The Cognitive Performance Scale; Normal and mildly impaired=0-1, Moderately impaired $=2-3$, Severely impaired=4-6. $2=$ Dementia diagnosis; Alzheimer (i1q) and other forms (i1r) included in the RAI/MDS instrument. $3=$ Missing value=1. $4=$ Chi-square test.

Dementia diagnosis and cognitive impairment vs. ED referrals and non referrals

Table 3 reveals that during a 12-month period older patients with a diagnosis of dementia were significantly less often referred to an $\mathrm{ED}(\mathrm{p}=0.010)$ compared to those without such a diagnosis ( $23 \%$ and $33 \%$ respectively). A similar pattern was evident when cognitive capacity was assessed by the CPSscale. The $26 \%$ of participants who had moderate to severe cognitive impairment (CPS 2-6) received significantly less referrals compared to the $34 \%$ with normal cognitive capacity $(\mathrm{p}=0.024)$.

\section{Multicomorbidity, health status and drug use in the three} sub-groups

The patients' health status profile is presented in three subgroups: dementia diagnosis and not referred to an ED; dementia diagnosis and referred; and no dementia diagnosis and not referred. It was revealed that those in the first group had significantly impaired cognitive and functional capacities. Their CPS total was significantly higher at $4.45 \pm 1.3$ (meanSD) as was their ADL total of $10.96 \pm 5.3$ (meanSD) compared to the other groups (Table 4 ). These patients also had reduced ability to understand others, $39 \%$ usually understood messages, $38 \%$ had adequate vision, $65 \%$ had adequate hearing with a hearing aid and $81 \%$ had wanderer behaviour, all of which can cause problems in basic nursing care. In contrast, $61 \%$ of the individuals who had dementia and were referred to an ED were reported to usually understand messages. According to Table 4, multicomorbidity was significantly less among patients with no dementia diagnosis and not referred. However, low BMI values and daily pain were common in all three groups and there were no significant differences between them.

Table 3

Dementia diagnosis and cognitive capacity among older patients referred and not referred from nursing homes to an Emergency Department over a 12 month period $(\mathrm{n}=719)$

\begin{tabular}{lccc}
\hline & $\begin{array}{c}\text { Referrals } \\
\mathbf{n = 2 0 9}(\boldsymbol{\%})\end{array}$ & $\begin{array}{c}\text { Non referrals } \\
\mathbf{n = 5 1 0}(\boldsymbol{\%})\end{array}$ & $\mathbf{p}^{2}$ \\
\hline $\begin{array}{l}\text { Dementia diagnosis } \\
\text { No dementia diagnosis }\end{array}$ & $59(23)$ & $199(77)$ & \\
$\begin{array}{l}\text { The Cognitive Performance } \\
\text { Scale, CPS-scale 0-6 } \\
\text { Normal cognitive capacity, }\end{array}$ & $83(34)$ & $311(68)$ & 0.010 \\
$\begin{array}{l}\text { CPS-scale 0-1 } \\
\text { Moderately and severely } \\
\text { impaired CPS-scale 2-6 }\end{array}$ & $126(26)$ & $158(66)$ & \\
\hline
\end{tabular}

Dementia diagnoses; Alzheimer (i1q) and other forms (i1r) included in the RAI/MDS instrument; 2 = Chi-square test. 3 = CPS-scale 0-6; The Cognitive Performance Scale; Normal and mildly impaired $=0-1$, Moderately impaired $=2-3$, Severely impaired $=4-6$.

Table 5 illustrates that drug consumption was high with wide variation. Patients with no dementia diagnosis and not referred to an ED had the highest consumption $(7.59 \pm 8.3$, meanSD) but no significant differences were revealed between the groups. The use of neuroleptics among patients with dementia, both referrals and non referrals, was significantly higher compared to the group of patients with no dementia diagnosis and not referred. The consumption of hypnotics was significantly higher among those with no dementia diagnosis and not referred.

Table 4

Multicomorbidity and health status of the nursing home patients divided into three groups; dementia diagnosis/not referred to an Emergency Department over a one-year period, dementia diagnosis/referred and no dementia diagnosis/not referred

\begin{tabular}{|c|c|c|c|c|}
\hline RAI/MDS variables & $\begin{array}{c}\text { Dementia diagnosis/ } \\
\text { not referred }^{1} \\
\text { n=197 }(\%)\end{array}$ & $\begin{array}{c}\text { Dementia diagnosis/ } \\
\text { referred } \\
\mathbf{n = 5 9}(\%)\end{array}$ & $\begin{array}{c}\text { No dementia diagnoses/ } \\
\text { not referred } \\
\text { n=312 }(\%)\end{array}$ & $\mathbf{p}^{4}$ \\
\hline Psychiatric diagnosis & $40(20)$ & $8(13)$ & $70(22)$ & 0.279 \\
\hline Cardiovascular diagnosis & $100(51)$ & $36(61)$ & $181(58)$ & 0.299 \\
\hline Multicomorbidity, nos 1-4 & $166(84)$ & $50(85)$ & $237(76)$ & \\
\hline no $5+$ & $31(16)$ & $9(15)$ & $50(16)$ & $\leq 0.001$ \\
\hline CPS-sum ${ }^{2}$ & $4.45 \pm 1.3$ & $4.27 \pm 1.2$ & $2.18 \pm 2.1$ & $\leq 0.001$ \\
\hline ADL-sum ${ }^{3}$ & $10.9 \overline{6} \pm 5.3$ & $9.56 \pm 5.1$ & $8.88 \pm \overline{ \pm} 5.3$ & $\leq 0.001$ \\
\hline Daily pain & $54(\overline{2} 7)$ & $11(\overline{19})$ & $99 \overline{(32})$ & -0.140 \\
\hline Pressure ulcer & $13(7)$ & $3(4)$ & $20(6)$ & 0.931 \\
\hline BMI $<22$ & $83(42)$ & $19(32)$ & $106(34)$ & 0.051 \\
\hline
\end{tabular}

1 = 1 Missing value, 2 = CPS-sum, 1-6; the Cognitive Performance Scale; Normal and mildly impaired=0-1, Moderately impaired= 2-3, Severely impaired=4-6. 3 = ADL-sum, 4-18; Activities of Daily living; Normal/moderately impaired function (4-9) and severe dysfunction (10-18), p4=Kruskal-Wallis test (meanSD) and Chi-square test. 
Table 5

Drug use profile of the three groups of older nursing home patients; dementia diagnosis/not referred to an Emergency Department over a one-year period, dementia diagnosis/ referred and no dementia diagnosis/not referred

\begin{tabular}{|c|c|c|c|c|}
\hline RAI/MDS variables & $\begin{array}{c}\text { Dementia diagnosis/ } \\
\text { not referred }^{1} \\
\text { n=197 }(\%)\end{array}$ & $\begin{array}{c}\text { Dementia diagnosis/ } \\
\text { referred } \\
\mathbf{n = 5 9}(\%)\end{array}$ & $\begin{array}{c}\text { No dementia diagnoses/ } \\
\text { not referred } \\
\text { n=312 }(\%)\end{array}$ & $\mathbf{p}^{4}$ \\
\hline Drug use in the previous week & $6.81 \pm 9.8$ & $5.49 \pm 2.6$ & $7.59 \pm 8.3$ & 0.176 \\
\hline Neuroleptica & $47(24)$ & $12(20)$ & $33(11)$ & $\leq 0.001$ \\
\hline Sedatives & $60(31)$ & $12(20)$ & $58(19)$ & 0.066 \\
\hline Antidepressives & $71(36)$ & $20(34)$ & $91(29)$ & 0.500 \\
\hline Hypnotics & $47(24)$ & $12(20)$ & $94(30)$ & 0.032 \\
\hline Diuretics & $82(42)$ & $25(42)$ & $158(51)$ & 0.092 \\
\hline Analgesics & $80(41)$ & $20(34)$ & $133(43)$ & 0.432 \\
\hline
\end{tabular}

$1=1$ Missing value, $\mathrm{p} 2=$ Kruskal-Wallis test (meanSD) and Chi-square test.

\section{Discussion}

\section{Discussion of results}

Comprehensive cognitive impairment was reported but did not correspond with dementia diagnoses, which were significantly fewer. Patients diagnosed with dementia or cognitive decline according to CPS scores were referred to EDs significantly less frequently compared to those without such a diagnosis. These patients had reduced ability to understand others, inadequate vision and hearing as well as in many cases wanderer behaviour, all of which can cause nursing care problems. Significantly decreased physical capacity was reported over a year among patients with a diagnosis of dementia, both those with and without referrals to an ED. Individuals who had a diagnosis of dementia and were referred usually understood messages. Comprehensive multicomorbidity was reported in all individuals, although it was significantly less among those with no diagnosis of dementia and no referral to an ED. Low BMI values and daily pain were common among all patients. A recent review about pain among older resident in NHs (34) including 27 articles between 1990-2009 report of high pain intensity and that the drug treatment was insufficient in particular among individuals with impaired cognitive capacity. Furthermore, it was evident that assessments of pain among persons with in particular severe dementia are difficult since the caregivers have to rely on observation scales. However, studies have shown that relatives and caregivers who know the patients seem to be able to assess and interpret symptoms of pain $(35,36)$.

Drug consumption was high for all patients, but there were significantly more neuroleptics used by those with a dementia diagnosis. A high rate of psychotropic drug use reflects poor quality drug prescription, since these drugs should be used sparingly among older patients with cognitive impairments (16). Some behaviors, such as wandering and screaming are difficult to manage and it is tempting to use neuroleptics but nevettheless, there is no support in the literature that supports the use of neuroleptics for such conditions (38).

The frequency of dementia diagnoses has been reported to increase in line with age (36). The study was performed in
2002. During the last decade powerful attention with national guidelines and a register (SweDem) for dementia diseases have been introduced in Sweden. These efforts have probably resulted in a higher proportion of identified persons with dementia. However, continuing efforts are needed since recent studies report that dementia still is undetected $(25,26)$. We argue that it is important to use medical diagnoses as a basis for nursing care planning and follow-ups for all patients. There is a risk for individuals with unidentified dementia diagnoses that both their medical and nursing care need will pass unmet. Fillit (39) stressed that dementia may be concealed by co-morbidities in patients who live in clinical settings. This in turn may explain why dementia is usually undetected or neglected among older patients with e.g. hip fracture or pneumonia on admission to hospital. Moreover, patients with a severe hearing impairment were found to have a higher risk of developing dementia. It has been suggested that dementia could be over diagnosed among these patients but also that impaired hearing can contribute to dementia due to social isolation (40).

Multicomorbidity, e.g. stroke (41), heart and circulatory problems (42), has been found to increase readmission to hospital among older patients. One way of calculating multimorbidity is to count the number of diseases a person has without weighting or ranking them (43). In the present study, the participants presented a high percentage of multicomorbidity, both those who had dementia diagnoses and were referred and those not referred to an ED over a year. Condelius et al. (6) confirmed that multicomorbidity predicts the number of admissions to hospital.

A review article by Murray et al. (44) described that $\mathrm{NH}$ patients are the most vulnerable members of society and many are at risk of referrals to EDs. It was suggested that these patients' safety could be improved if an interdisciplinary patient centered approach was implemented and if geriatric education for ED staff was promoted. Other studies have found that older patients are not prioritized at EDs as well as given the shortest amount of time, both in the corridor and the treatment room $(45,5)$.

From the ED nurses' point of view it is necessary to have an adequate basic knowledge of various illnesses in order to 
provide good nursing care. They must be able to observe symptoms, understand improvement or deterioration in the patient's health status as well as react appropriately and effectively in emergency situations. It is important that they try to understand and gain insight into the older patient's situation (5). Geriatric ED nurse education is required in order to improve ED nurses' competencies and enable them to provide high quality care for older people admitted to EDs. After such education, ED nurses self-rated their ability, reporting an improvement concerning assessments of dementia, polypharmacy, pain and atypical presentation of illnesses (46).

\section{Methodological considerations}

These results are considered reliable despite some limitations. The study was performed in NHs and the definition of the setting is not always clear, which highlights the importance of regularly determining the individuals' health status, irrespective of setting. Many different caregivers conducted the RAI/MDS assessments, which can weaken interrater reliability. Thus, education and practical training in the use of the instrument is essential. The RAI/MDS interrater reliability was tested with acceptable to good figures $(29,32)$. Improvement measures were to provide education and practical training of the instrument. The RAI/MDS instrument concerns medical diagnoses and this information was retrieved from the patients' medical records.

\section{Conclusion}

This study revealed comprehensive cognitive decline among $\mathrm{NH}$ patients that did not correspond with dementia diagnoses, which were significantly fewer. Patients with impaired cognitive capacity were significantly less frequently referred to EDs compared to those with no cognitive decline, which is supported by the findings of Kihlgren et al. (1). Patients diagnosed with dementia, both referrals and non referrals to EDs over a 12-month period had significant physical decline, a high percentage of multicomorbidity and used a great number of drugs, in particular neuroleptica. Underestimated and undetected dementia has previously been described $(29,32)$, which is confirmed by the present study. NH patients are the most vulnerable members of society and many are at risk of ED referrals. Older patients need acute care and it should not be denied them. However, in addition to an interdisciplinary patient centred approach and promotion of geriatric education for ED staff (2), the ED milieu must be improved and become more adaptable.

Our study reveals that NH patients with cognitive decline and/or dementia are significantly less often referred to an ED despite the fact that they are as sick as or even sicker than patients without such problems. According to the literature review, this group of patients is at risk of being undertreated as well as badly treated at EDs. A dementia diagnose will support the nurses to further understand and provide an individual need of care. The question is whether this group of the most vulnerable patients has low priority and is undertreated or whether ED referrals are avoided in order to provide good care in NHs for as long as possible. Further research is needed, such as observational studies that focus on cognitively impaired patients in order to detect what is actually done or could be done in referral situations.

\section{References}

1. Kihlgren A, Wimo A, Mamhidir A-G. Older patients referred by community nurses to Emergency Departments - a descriptive cross-sectional follow-up study in a Swedish context. Submitted.

2. Muntlin A, Gunningberg L, Carlsson M. (2006) Patients' perceptions of quality of care at an emergency department and identification of areas for quality improvement. Clin Nurs 15: 1045-1056.

3. Kihlgren AL, Nilsson M, Skovdahl K, Palmblad B, Wimo A (2004) Older patients awaiting emergency department treatment. Scand J Caring Sci 18: 169-176.

4. Grief CL. (2003) Patterns of ED use and perceptions of the elderly regarding their emergency care: a synthesis of recent research. Emerg Nurs 29: 122-126.

5. Kihlgren AL, Nilsson M, Sørlie V. (2005) Caring for older patients at an emergency department -- emergency nurses' reasoning. J Clin Nurs 14: 601-608.

6. Downing A, Wilson R. (2005) Older people's use of Accident and Emergency services. Age Ageing 34: 24-30.

7. Condelius A, Edberg AK, Jakobsson U, Hallberg IR. (2008) Hospital admissions among people $65+$ related to multimorbidity, municipal and outpatient care. Arch Gerontol Geriatr 46: 41-55.

8. Condelius A, Hallberg IR, Jakobsson U. (2010) Medical healthcare utilization as related to long-term care at home or in special accommodation. Arch Gerontol Geriatr 51:250-256.

9. Carter L, Skinner J, Robinson S. (2009) Patients from care homes who attend the emergency department: could they be managed differently. Emerg Med J 26:259262.

10. Akner G. (2004) Multisjuklighet hos Äldre. Analys, handläggning och förslag om Äldrevårdscentral (Multi-diseases among elderly. Analysis, management and proposals concerning an Elder care centre) (In Swedish). Liber AB, Bulls House of Graphics.

11. Hansagi H, Olsson M, Sjöberg S, Tomsson Y, Göransson S. (2001) Frequent Use of the Hospital Emergency Department Is Indicative of High Use of Other Health Care Services. Ann Emerg Med 37: 561-567.

12. Swedish Associations and local Authorities and Regions. (2011) On the Swedish municipal and county council finances - may 2011. Verksamhet och ekonomi i landsting och regioner. Statistik. Report in Swedish, SKL, Stockholm. http://www.skl.se/vi_arbetar_med/socialomsorgochstod/aldre/kortfakta-aldreomradet

13. Swedish Association of Local Authorities and the Federation of Swedish County Councils. (2004) www.skl.se

14. National Board of Health and Welfare. (2009) Vård och omsorg om äldre- en lägesrapport (Caring for older people - a situation report 2009). (In Swedish) Socialstyrelsen, Stockholm. Access 2010-03-12

15. Swedish Associations and local Authorities and Regions. (2011) Sveriges kommuner och landsting (SKL) Äldreområdet - kortfakta. Report in Swedish, SKL, Stockholm. http://www.skl.se/vi_arbetar_med/socialomsorgochstod/aldre/kortfakta-aldreomradet

16. Bergman A, Olsson J, Carlsten A, Waern M, Fastbom J. (2007) Evaluation of the quality of drug therapy among elderly patients in nursing homes. Scand J Prim Health Care 25: 9-14.

17. Olsson J, Bergman A, Carlsten A, Oké T, Bernsten C, Schmidt IK, Fastbom J. (2010) Quality of drug prescribing in elderly people in nursing homes and special care units for dementia: a cross-sectional computerized pharmacy register analysis. Clin Drug Investig 30: 289-300.

18. Wimo A, Winblad B, Jönsson L. (2007) An estimate of the total worldwide societal costs of dementia in 2005. Alzheimers Dement 3: 81-91.

19. Mamhidir AG, Kihlgren M, Kihlgren A, Wimo A. (2006) Underweight, weight loss and related risk factors among older adults in sheltered housing--a Swedish follow-up study. Nutr Health Aging 10: 255-262.

20. Nordberg G, Wimo A, Jönsson L, Kåreholt I, Sjölund BM, Lagergren M, von Strauss, E. (2007) Time use and costs of institutionalised elderly persons with or without dementia: results from the Nordanstig cohort in the Kungsholmen Project--a population based study in Sweden. Int J Geriatr Psychiatry 22, 639-648.

21. Ragneskog H, Gerdner LA, Hellström L. (2001) Integration of lucid individuals and agitated individuals with dementia in different care units. Clin Nurs 10: 730-736.

22. Cwinn MA, Forster AJ, Cwinn AA, Hebert G, Calder L, Stiell IG (2009) Prevalence of information gaps for seniors transferred from nursing homes to the emergency department. CJEM 11:462-471. 


\section{JNHA: CLINICAL NEUROSCIENCES}

23. Dalawari P, Duggan J, Vangimalla V, Paniagua M, Armbrecht ES. (2011) Patient transfer forms enhance key information between nursing homes and emergency department. Geriatr Nurs 32:270-275.

24. McCloskey RM. (2011) A qualitative study on the transfer of residents between a nursing home and an emergency department. J Am Geriatr Soc 59:717-724.

25. Fillit HM, Simon ES, Doniger GM, Cummings JL. (2008). Practicality of a computerized system for cognitive assessment in the elderly. Alzheimers Dement 4 $14-21$.

26. Douzenis A, Michopoulos I, Gournellis R, Christodoulou C, Kalkavoura C, Michalopoulou PG, Fineti K, Patapis P, Protopapas K, Lykouras L. (2010) Cognitive decline and dementia in elderly medical inpatients remain underestimated and underdiagnosed in a recently established university general hospital in Greece. Arch Gerontol Geriatr 50:147-150.

27. Michalopoulou PG, Fineti K, Patapis P, Protopapas K, Lykouras L. (2010) Cognitive decline and dementia in elderly medical inpatients remain underestimated and underdiagnosed in a recently established university general hospital in Greece. Arch Gerontol Geriatr 50: 147-150.

28. Hustey FM, Meldon SW, Smith MD, Lex CK. (2003) The effect of mental status screening on the care of elderly emergency department patients. Ann Emerg Med 41:678-684

29. Hawes C, Morris JN, Phillips CD, Mor V, Fries BE, Nonemaker S. (1995) Reliability estimates for the Minimum Data Set for nursing home resident assessment and care screening (MDS). Gerontologist 35: 172-178.

30. Morris JN, Hawes C, Fries BE, Phillips CD, Mor V, Katz S, Murphy K, Drugovich ML, Friedlob AS. (1990) Designing the national resident assessment instrument for nursing homes. Gerontol 3: 293-307.

31. Morris JN, Nonemaker S, Murphy K, Hawes C, Fries BE, Mor V, Phillips C. (1997) A commitment to change: revision of HCFA's RAI. J Am Geriatr Soc 45: 1011-1016.

32. Morris JN, Fries B, Mehr, DR, Hawes C, Phillips C, Mor V, Lipsitz LA. (1994) MDS Cognitive Performance Scale. Gerontol 49: M174-182.

33. Fries BE, Hawes C, Morris JN, Phillips CD, Mor V, Park PS. (1997) Effect of the National Resident Assessment Instrument on selected health conditions and problems. Am Geriatr Soc 45: 994-1001.

34. Takai Y, Yamamoto-Mitani N, Okamoto Y, Koyama K, Honda A. (2010) Literature review of pain prevalence among older residents of nursing homes. Pain Manag Nurs

\section{$11,209-223$}

35. Weiner D. Peterson B. Ladd K, McConnell E, Keefe F. (1999) Pain in nursing home residents: An exploration of prevalence, staff perspectives, and practical aspects of measurement. Clin J Pain 15, 92-101.

36. Maas ML., Reed D., Park M., Specht JP., Schutte D., Kelley LS., Swanson EA., Trip-Reimer T. \& Buckwalte KC. (2004). Outcomes of Family Involvement in Care Intervention for Caregivers of Individuals with Dementia. Nurs Res 53, 76-86.

37. SBU. (2008) Dementia. A systematic review. Stockholm: Staten beredning för medicinsk utvärdering, SBU 2008 (The Swedish Council on Technology Assessment in Health Care) Report No.: 172E/1-3.

38. Wang XP, Ding HL. (2008) Alzheimer's disease: epidemiology, genetics and beyond. Neurosci Bull 24: 105-109.

39. Fillit HM. (2000) The pharmacoeconomics of Alzheimer's disease. Am J Manag Care 6: S1139-1144.

40. Lin FR, Metter EJ, O'Brien RJ, Resnick SM, Zonderman AB, Ferrucci L. (2011) Hearing Loss and Incident Dementia. Arch Neurol 68: 214-220.

41. Claesson L, Gosman-Hedström G, Lundgren-Lindquist B, Fagerberg B, Blomstrand C. (2002) Characteristics of elderly people readmitted to the hospital during the first year after stroke. The Göteborg 70+ stroke study. Cerebrovasc Dis 14: 169-176.

42. Timms J, Parker VG, Fallat EH, Johnson WH. (2002) Documentation of characteristics of early hospital readmission of elderly patients. A challenge for inservice educators. J Nurses Staff Dev 18:136-143.

43. Rochon PA, Katz JN, Morrow LA, McGlinchey-Berroth R, Ahlquist MM, Sarkarat $\mathrm{M}$, Minaker KL. Comorbid illness is associated with survival and length of hospital stay in patients with chronic disability. A prospective comparison of three comorbidity indices. Med Care. 1996 Nov;34(11):1093-101.

44. Murray LM, Laditka SB (2010) Care transitions by older adults from nursing homes to hospitals: implications for long-term care practice, geriatrics education, and research. Am Med Dir Assoc 11: 231-238.

45. Nyström M, Dahlberg K, Carlsson G. (2003) Non-caring at an emergency care unit a life-world hermeneutic analysis of an efficiency-driven organization. Int J Nurs Stud 40: 760-769

46. Désy PM, Prohaska TR. (2008) The Geriatric Emergency Nursing Education (GENE) course: an evaluation. J Emerg Nurs 34: 396-402.

\section{The Journal of Frailty \& Aging}

The Journal of Frailty \& Aging is a peer-reviewed international journal aimed at presenting articles that are related to research in the area of aging and age-related (sub)clinical conditions. In particular, the journal publisheshigh-quality papers describing and discussing social, biological, and clinical features underlying the onset and development of frailty in older persons. The Journal of Frailty \& Aging is composed by five different sections :

- Biology of frailty and aging: In this section, the journal presents reports from preclinical studies and experiences focused at identifying, describing, and understanding the subclinical pathophysiological mechanisms at the basis of frailty and aging.

- Physical frailty and age-related body composition modifications: Studies exploring the physical and functional components of frailty are contained in this section. Moreover, since body composition plays a major role in determining physical frailty and, at the same time, represents the most evident feature of the aging process, special attention is given to studies focused on sarcopenia and obesity at older age.

- Neurosciences of frailty and aging: The section presents results from studies exploring the cognitive and neurological aspects of frailty and age-related conditions. In particular, papers on neurodegenerative conditions of advanced age are welcomed.

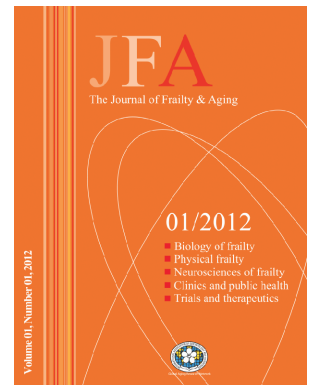

- Frailty and aging in clinics and public health: This journal's section is devoted at presenting studies on clinical issues of frailty and age-related conditions. This multidisciplinary section particularly welcomes reports from clinicians coming from different backgrounds and specialties dealing with the heterogeneous clinical manifestations of advanced age. Moreover, this part of the journal also contains reports on frailty- and age-related social and public health issues.

- Clinical trials and therapeutics: This final section contains all the manuscripts presenting data on (pharmacological and non-pharmacological) interventions aimed at preventing, delaying, or treating frailty and age-related conditions.

The Journal of Frailty \& Aging is a quarterly publication of original papers, review articles, case reports, controversies, letters to the Editor, and book reviews. Manuscripts will be evaluated by the editorial staff and, if suitable, by expert reviewers assigned by the editors. The journal particularly welcomes papers by researchers from different backgrounds and specialities who may want to share their views and experiences on the common themes of frailty and aging.

\section{Please consult : http://www.jfrailtyaging.com}

